\title{
Tuberculosis of the Prostate Gland Masquerading Prostate Cancer: A Case Report
}

\author{
Sani Ali Aji ${ }^{*}$, Sani Usman Alhassan ${ }^{1}$, Sharfuddeen Abbas Mashi ${ }^{1}$, Muhammad Ibrahim Imam ${ }^{2}$ \\ ${ }^{1}$ Urology Unit, Bayero University/Aminu Kano Teaching Hospital, Kano, Nigeria \\ ${ }^{2}$ Department of Pathology, Bayero University/Aminu Kano Teaching Hospital, Kano, Nigeria \\ Email: "saniaji2004@yahoo.com
}

Received September 25, 2013; revised October 21, 2013; accepted October 28, 2013

Copyright (C) 2013 Sani Ali Aji et al. This is an open access article distributed under the Creative Commons Attribution License, which permits unrestricted use, distribution, and reproduction in any medium, provided the original work is properly cited.

\begin{abstract}
Tuberculosis is one of the most important infectious diseases, particularly in developing countries. Involvement of the prostate gland is very rare. We present a 70-year-old man who presented with low back pain and progressive weakness of the lower limbs associated with irritative lower urinary tract symptoms. Prostate gland was enlarged, hard and nodular. Prostate specific antigen was $6 \mathrm{ng} / \mathrm{ml}$, Erythrocytes sedimentation rate was $130 \mathrm{~mm} / \mathrm{hr}$ and Monteux was positive. Prostate biopsy revealed features of tuberculosis and lumbosacral radiograph revealed features of Pott's disease. Diagnosis of disseminated tuberculosis with prostate involvement was made and patient was placed on anti-tuberculosis drugs with good response.
\end{abstract}

Keywords: Disseminated Tuberculosis; Prostate Gland; Diagnosis

\section{Introduction}

Tuberculosis is one of the most important infectious disease, particularly in developing countries like Nigeria. Approximately one third of the world population is infected with tuberculosis [1]. It has been estimated that the genus "mycobacteria" causes more suffering for the humans than all the other bacterial genera combined [2].

Pulmonary tuberculosis is the most common form of the disease and comprises of $68.4 \%$ of all cases, $20 \%$ to $25 \%$ of cases are extrapulmonary, while only $27 \%$ of the extrapulmonary tuberculosis involves the genitourinary system [3]. Tuberclosis of the prostate gland is seen in only $2.6 \%$ of genitourinary tuberculosis [1].

Tuberculosis involving the prostate gland, apart from being rare, can also mimic cancer of the prostate as well as BPH and therefore requires a high index of suspicion.

Here we present a case of disseminated tuberculosis involving the spine and the prostate gland, thereby masquerading as prostate cancer.

\section{Case Report}

A 70-year-old man was referred to our clinic with a working diagnosis of prostate carcinoma from General

${ }^{*}$ Corresponding author. outpatient department of our hospital.

He presented with low back pain for 11 months and inability to walk for 1 month. He had associated irritative lower urinary tract symptoms but no obstructive symptoms. No history of haematuria. No history of trauma.

No history of fever, cough, contact with a person with chronic cough or excessive night sweats, however he had anorexia and progressive weight loss.

On examination, he was found to be an elderly man on a wheelchair, he was not pale, afebrile, not dehydrated, no significant peripheral lymphadenopathy and no pedal oedema. Chest, cardiovascular and abdominal examinations were essentially normal, however on rectal examination; the prostate was enlarged, hard and nodular. Power on both lower limbs was 3/5. There was no sensory impairment. Examination of the spines did not reveal any abnormality.

His serum urea, electrolytes and creatinine were within normal limits. Prostate specific antigen was $6 \mathrm{ng} / \mathrm{ml}$. Erythrocytes sedimentation rate was $130 \mathrm{~mm} / \mathrm{hr}$ and Manteux test was positive. Prostatic biopsy revealed poorly preserved prostatic tissue with few acini, the abundant fibromascular stroma shows predominantly caseous necrosis, occational "horse-shoe" shaped multinucleated giant cells and lymphocytic infiltrates (Figures 1 and 2). Lumbosacral radiographs reveal reduction of space- $-\mathrm{L} 1 / \mathrm{L} 2$, 


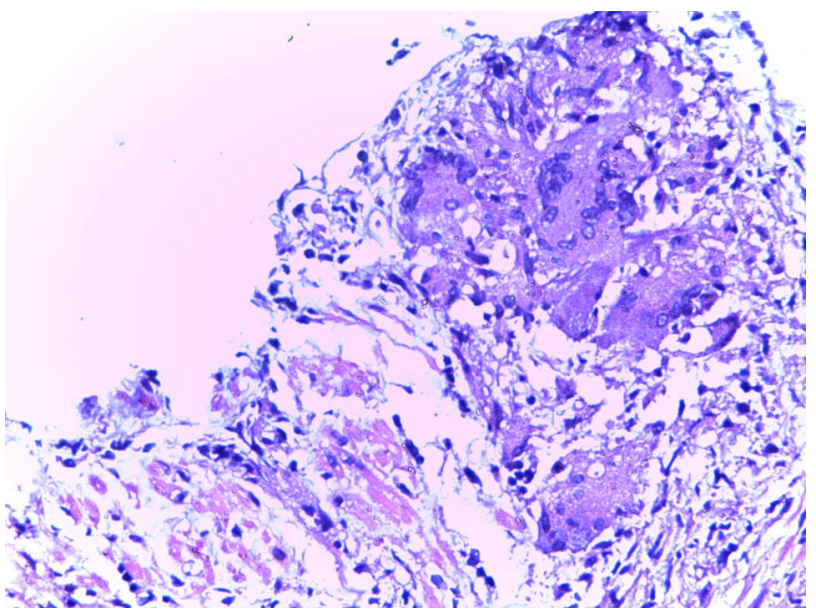

Figure 1. Showing caseous necrosis, occational "horse-shoe" shaped multinucleated giant cells and lymphocytic infiltrates (40× magnification).

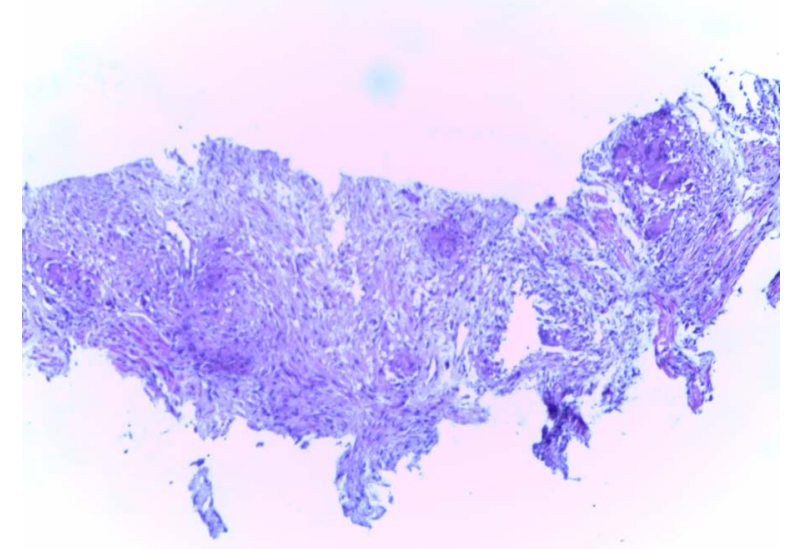

Figure 2. At lower magnification showing the same $(10 \times$ magnification).

L3/L4; with osteolytic changes, reduction in height of L5 and wide spread osteophytes (Figures 3 and 4). Chest $\mathrm{x}-$ ray was normal.

Based on the above findings, diagnosis of Disseminated Tuberculosis was made; patient was also reviewed by Orthopedic Surgeon and was then commenced on anti-tuberculosis drugs with good response.

\section{Discussion}

Tuberculosis (TB) remains a major public health problem in developing countries [4]. It can involve any organ system, however when it involves two or more organ system, it is referred to as Disseminated Tuberculosis (DTB) [2]. Involvement of the prostate gland is very rare, but can occur either in isolation, [5] with other Genitourinary organs like epididymis and seminal vesicle, or as part of a DTB [2].

TB involving the prostate may be very difficult to differentiate from the carcinoma of the prostate, particularly

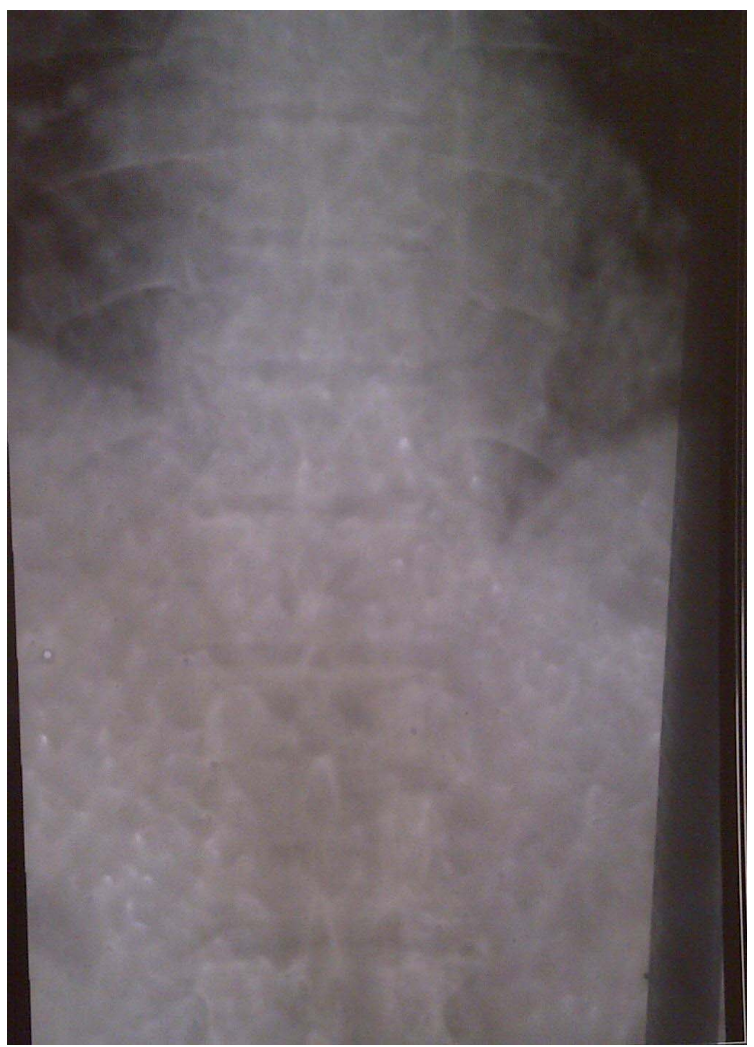

Figure 3. Showing reduction of space-T12/L1 with osteolytic changes.

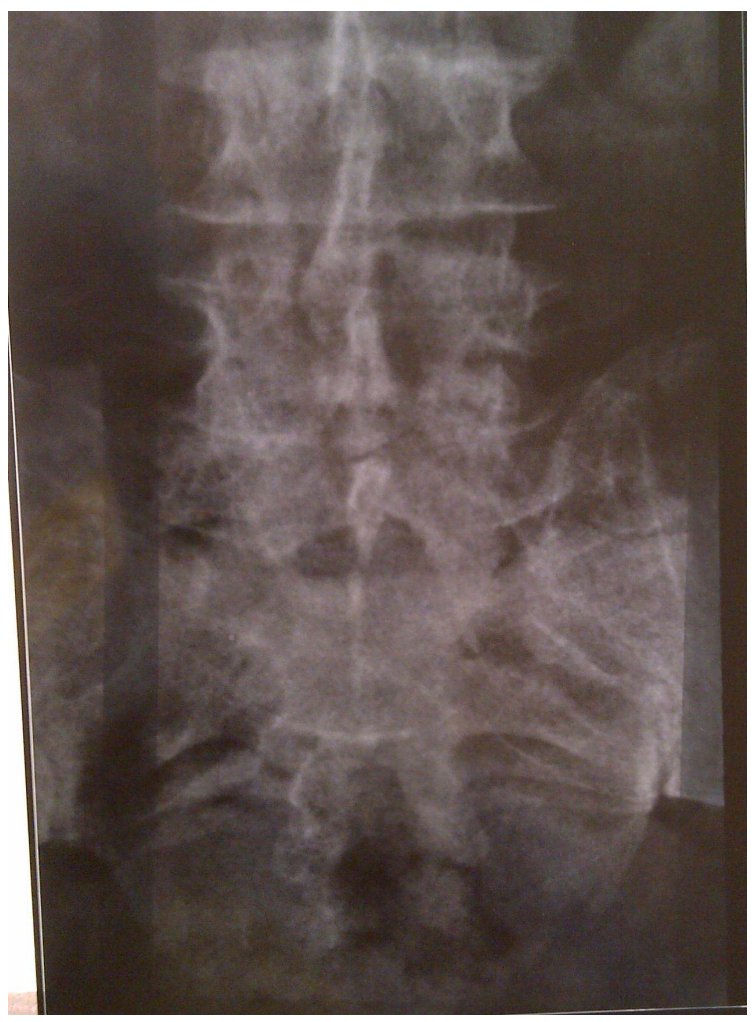

Figure 4. Showing reduction in height of L5 and wide spread osteophytes. 
when prostate is hard and nodular on digital rectal examination [6]. Prostate TB is mainly diagnosed incidentally, either following trucut needle biopsy of the prostate for a suspected carcinoma of the prostate, [7] or after prostatectomy specimen for Benign Prostatic Hyperplasia is subjected to histology [8]. Very rarely prostate cancer can co-exist with TB of the Prostate [9].

In this case report, the patient was initially seen by a Family Physician, who made a diagnosis of metastatic carcinoma of the Prostate based on the Paraparesis, and the findings of a hard nodular prostate on rectal examination.

K. Huang et al. in Taiwan, conducted a study on 10 patients over a period of 10 years, who all presented with digital rectal examination findings suggestive of Prostate cancer, but needle biopsy of the prostate revealed tuberculosis [6].

A. Kostakopoulos et al. also presented 5 cases of TB of the prostate, all of which were incidental histologic findings after Trans-urethral resection of the Prostate [10].

P. M. Karup et al. and M. A. Gafur et al. have all presented a patient with lower urinary tract symptoms and prostate biopsy revealed granulomatous prostatitis [11, 12].

We presented this case because it masqueraded as a typical case of metastatic carcinoma of the prostate and was only revealed after prostatic biopsy was done.

\section{Conclusion}

Tuberculosis of the prostate, though rare, can mimic prostate cancer as well as BPH. A high index of suspicion is therefore needed in order to avoid misdiagnosis particularly those practicing in the developing countries.

\section{REFERENCES}

[1] K. Akhtar, "Tuberculous Granuloma with Langhan’s Giant Cells in the Prostate," Kemcolian Journal of Medical
Sciences, Vol. 1, No. 1, 2012.

[2] R. Mittel, R. Sudha, M. Veeraraghavan, et al., "Disseminated Tuberculosis with Involvement of the Prostate-A Case Report," The Indian Journal of Tuberculosis, Vol. 57, No. 1, 2010, pp. 48-52.

[3] S. Chandra, H. Chandra, N. Chauhan, et al., "Male Genitourinary Tuberculosis-13 Years' Experience at a Tertiary Centre in India," Southeast Asian Journal of Tropical Medicine and Public Health, Vol. 43, No. 2, 2012, pp. 364-369.

[4] N. Gupta, A. K. Mandal and S. K. Singh, "Tuberculosis of the Prostate and Urethra-A Review," Indian Journal of Urology, Vol. 24, No. 3, 2008, pp. 388-391. http://dx.doi.org/10.4103/0970-1591.42623

[5] L. R. G. Cradon, “Tuberculosis of the Prostate,” The New England Journal of Medicine, Vol. 147, 1902, pp. 17-19. http://dx.doi.org/10.1056/NEJM190207031470106

[6] K. Huang, H. Wu, Y. Hsu, et al., "Tuberculosis of the Prostate,” Journal of Urology, Vol. 12, No. 3, 2001.

[7] R. Klis, D. Mioczkowski and M. Sosnowski, "Tuberculosis of the Prostate-Rare case report," Urologia Polska, 2006.

[8] N. Bhargava and S. K. Bhargava, "Primary Tuberculosis of the Prostate," Indian Journal of Radiology and Imaging, Vol. 13, 2003, pp. 236-237.

[9] H. Zhang, Y. Xu and R. Liu, "A Rare Case of Prostatic Tuberculosis Accompanied by Prostate Cancer,” BJUI, 2010.

[10] A. Kostokopoulos, G. Economou and D. Picramenos, “Tuberculosis of the Prostate," International Urology and Nephrology, Vol. 30, No. 2, 1998, pp. 153-157. http://dx.doi.org/10.1007/BF02550570

[11] P. M. Krarup, Z. Kamper-Jorqensen and S. Oster, "Tuberculous Prostatitis in a Previously Healthy Danish Man,” Uqeskrift for Laeqer, Vol. 170, No. 1, 2008, p. 58.

[12] M. A. Gafur, M. S. Talukder and S. S. Siddiqua, "Tuberculous Prostatitis-A Case Report," Mymensingh Medical Journal, Vol. 11, No. 1, 2002, pp. 39-41. 